\title{
Papillary Renal Adenoma of Distal Nephron Differentiation in a Horse
}

\author{
Kazuya MATSUDA ${ }^{1)}$, Yousuke KOUSAKA ${ }^{1)}$, Natsuko NAGAMINE ${ }^{2)}$, Nobuo TSUNODA ${ }^{3)}$ and Hiroyuki TANIYAMA ${ }^{1)}$ \\ ${ }^{1)}$ Department of Veterinary Pathology, School of Veterinary Medicine, Rakuno Gakuen University, Ebetsu, Hokkaido 069-8501, \\ ${ }^{2)}$ Northern Farm, Abira, Hokkaido 059-1432 and ${ }^{3}$ Shadai Corporation Limited, Abira, Hokkaido 059-1432, Japan
}

(Received 21 November 2006/Accepted 14 March 2007)

ABSTRACT. A 20-year-old thoroughbred mare had a mass in the right kidney. The mass was encapsulated with fibrous capsule and composed of variably-sized papillary projections lined by a single layer of flattened to cuboidal neoplastic epithelial cells with no cytological and nuclear atypia. Immunohistochemically, the neoplastic cells were broadly positive for cytokeratin AE1/AE3 and granular staining for alpha-1-antitrypsin was focally detected; this immunohistochemical property was similar to that of the normal distal nephron. From these results, this case was diagnosed as papillary renal adenoma of distal nephron differentiation.

KEY WORDS: equine, kidney, neoplasm.

Primary renal tumors are as rare in horses as in other domestic animals $[11,22]$. A survey reviewing 3633 equine necropsy examinations revealed only 4 cases $(0.11 \%)$ of renal neoplasms [7]. Most reported cases of equine renal neoplasia are considered malignant, compared with few adenomas [3-5, 7, 18, 19, 23-25]. With respect to cells of origin, it has been mentioned that renal adenomas and carcinomas could arise from either proximal or distal tubules in humans $[6,8]$, but no distinctive study has been published in the veterinary literature without reference to canine neoplasms of proximal tubule origin $[2,10]$. In this note, we describe a case of renal adenoma in a horse and discuss the differentiation/derivation of the neoplasm.

A 20-year-old thoroughbred mare presented sudden onset of colic, and was clinically diagnosed as torsion of the large intestine. No other significant clinical signs had been observed before colic. The horse was administered flunixin meglumin without improvement in the clinical symptoms. The animal was considered to have a poor prognosis, and was euthanized.

Gross examination revealed axial torsion of the large colon, a small cholesterol granuloma in the choroid plexus of the left lateral ventricle, and a solitary mass, about $6 \mathrm{~cm}$ in diameter, in the right kidney. The renal mass was located throughout the cortex to inner medulla and was composed of dark red to yellow fragile tissue (Fig. 1). The mass was clearly demarcated from the adjacent parenchyma with an obvious fibrous capsule. There was no communication between the mass and the pelvic cavity. No significant gross lesions were detected in other organs.

Collected tissues were fixed in $10 \%$ formalin, dehydrated and embedded in paraffin wax. Sections were cut at $4 \mu \mathrm{m}$ thickness and stained with hematoxylin and eosin (HE). Immunohistochemical staining of the renal neoplasm was performed by the avidin-biotin-peroxidase complex

\footnotetext{
* Correspondence to: Matsuda, K., Department of Veterinary Pathology, School of Veterinary Medicine, Rakuno Gakuen University, 582, Bunkyodai-Midorimachi, Ebetsu, 069-8501, Japan e-mail:kmatsuda@rakuno.ac.jp
}

method. Primary antibodies used were mouse monoclonal antibodies to cytokeratin AE1/AE3 (CK) (Nichirei Bioscience, Tokyo, Japan), vimentin (Dako Cytomation, Glostrup, Denmark), and rabbit polyclonal antibody to alpha-1antitrypsin (AAT) (Zymed Laboratories, South San Francisco, CA). Non-neoplastic renal tissues adjacent to the neoplasm in the same sections served as controls.

Histologically, the tumor was composed of papillary growths of varying size projecting into the lumen (Fig. 2). A single layer of flattened to cuboidal cells with scant, lightly eosinophilic cytoplasm lined the projections. At the base, the lining cells continuously transitioned to cells of the same morphology lining the inner surface of the fibrous capsule. The stalks of the projections consisted of edematous fibrovascular stroma with partial hemorrhage and hemosiderin deposition, and scattered foci of lamellar calcium deposition. The neoplastic cells were uniform in cytological and nuclear morphology, and mitotic figures were absent. The adjacent renal parenchyma showed mild interstitial fibrosis. No metastases were observed in the organs examined. Immunohistochemically, neoplastic epithelium showed diffuse positivity for CK (Fig. 3a) and vimentin, and only focal granular staining for AAT (Fig. 4a). In non-neoplastic tissues, CK was broadly detected in the Henle's, distal and collecting tubules (Fig. 3b). Vimentin expression was observed in podocytes and parietal cells of Bowman's capsules, and in tubules with interstitial fibrosis adjacent to the mass. Vimentin was also positive in interstitial mesenchymal cells. AAT staining was diffusely but pale in proximal tubules and granular in collecting tubules (Fig. 4b).

Renal adenomas are defined as solitary, expansively growing, and non-encapsulated to insufficiently encapsulated but well-circumscribed masses in the cortex [10-12, 16]. They are composed of well-differentiated tubules and acini, and may be histologically subclassified as tubular, papillary, or solid based on the predominant histological pattern. The distinction of adenoma from renal carcinoma is sometimes difficult, because carcinoma may be grossly small, microscopically well-differentiated, but have meta- 

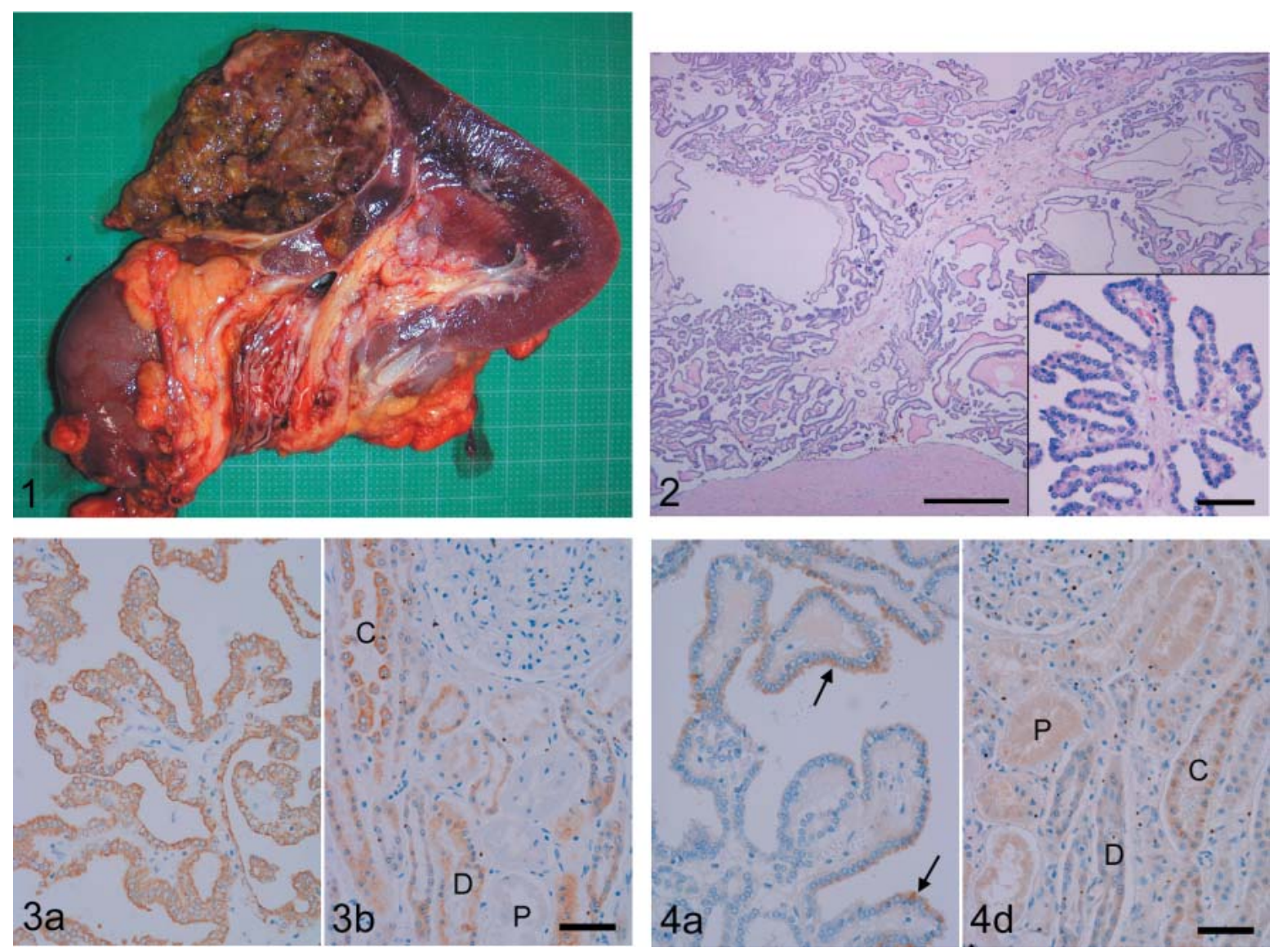

Fig. 1. Renal neoplasm clearly demarcated from adjacent parenchyma, located throughout the cortex to inner medulla without communication with the pelvic cavity in the right kidney.

Fig. 2. Papillary growths of neoplastic tissue projecting into the lumen (upward) from the fibrous capsule (base). HE stain. Bar=500 $\mu \mathrm{m}$. Inset: Projections lined by a single layer of neoplastic cells with round nuclei and scant, lightly eosinophilic cytoplasm. Bar=50 $\mu \mathrm{m}$.

Fig. 3. a. Neoplastic epithelium positive for cytokeratin AE1/AE3. b. Distal and collecting tubules positive for cytokeratin AE1/AE3 in the normal kidney. Immunohistochemistry for cytokeratin AE1/AE3 counterstained with hematoxylin. C, collecting tubule; D, distal tubule; P, proximal tubule, Bar $=50 \mu \mathrm{m}$.

Fig. 4. a. Neoplastic cells showing focal granular staining for alpha-1-antitrypsin (arrows). b. diffuse pale staing in proximal tubules and granular in collecting tubules for alpha-1-antitrypsin in the normal kidney. Immunohistochemistry for alpha-1-antitrypsin counterstained with hematoxylin. $\mathrm{C}$, collecting tubule; $\mathrm{D}$, distal tubule; $\mathrm{P}$, proximal tubule, $\mathrm{Bar}=50 \mu \mathrm{m}$.

static potential. Indeed, in humans, some authors have concluded that all renal cell neoplasms should be classified as carcinomas, even if the risk of metastasis is low $[15,17]$. Most reported cases of equine renal cell neoplasms were considered to be malignant due to their invasive expansion, tumor embolism, metastasis, or cytological and nuclear pleomorphism [3-5, 7, 18, 19, 23-25]. This case had a distinct fibrous capsule, no metastasis, and papillary structures of histologically benign tumor cells, so it was diagnosed as papillary renal adenoma.

The histogenesis of renal cell tumors in domestic animals remains to be clarified. It has been reported that some human renal cell adenomas or carcinomas originate from proximal tubules and others from distal tubules based on immunohistochemistry using lectin antibodies $[6,8]$. An antibody against $\mathrm{CK}$ has been used as a marker for distal and collecting tubules in humans and dogs $[9,14,20]$. In this horse, CK expression was observed broadly both in the neoplastic epithelium and in normal renal tissue in the same manner. AAT has been recognized as a satisfactory proximal tubule marker [14]. In this case, diffuse pale staining was detected in normal proximal tubules but not in neoplastic tissue; moreover, granular staining was seen in normal collecting tubules and a minority of neoplastic cells. From these results, it is concluded that this adenoma has a similar immunohistochemical property to that of the distal nephron. Vimentin staining in normal glomeruli was similar to that observed in dogs [26]. Vimentin is expressed in the fetal and neoplastic tubular epithelium but not in normal differentiated renal tubules; therefore, it is used as a marker of 
immaturity or dedifferentiation $[1,13]$. The positive reaction to vimentin in the tubular epithelium adjacent to the neoplasm may indicate an immature, regenerating state. The broad expression of vimentin in the neoplastic epithelium indicates a dedifferentiated state. Shen [21] proposed that all renal neoplasms may derive from pluripotential common stem cells, which are capable of differentiating toward different cell types of nephron. In this case, It is considered that neoplastic cells derived from epithelial cells of the distal nephron, and/or that pluripotential neoplastic stem cells differentiated to cells with a distal nephron phenotype. In animals, there may be several types of renal neoplasms. Further studies are needed to clarify the relevance between differentiation/derivation properties and the biological behavior of renal neoplasms.

\section{REFERENCES}

1. Barwick, K. W. 1990. pp. 4.2-4.7. In: Atlas of Diagnostic Immunohistopathology (True, L. D. ed.), Gower Medical Publishing, Philadelphia.

2. Baskin, G. B. and De Paoli, A. 1977. Vet. Pathol. 14: 591-605.

3. Berggren, P. C. 1980. J. Am. Vet. Med. Assoc. 176: 1252-1253.

4. Brown, P. J. and Holt, P. E. 1985. Equine Vet. J. 17: 473-477.

5. Cotchin, E. 1977. Equine Vet. J. 9: 16-21.

6. Fromowitz, F. B. and Bard, R. H. 1990. Semin. Urol. 8: 31-50.

7. Haschek, W. M., King, J. M. and Tennant, B. C. 1981. J. Am. Vet. Med. Assoc. 179: 992-994.

8. Hiasa, Y., Kitamura, M., Nakaoka, S., Ohshima, M., Konishi, N., Kitahori, Y., Hirao, K., Fukushima, Y., Tho, Y., Hayashi, I. and Ichijima, K. 1995. Oncology 52: 97-105.

9. Maclennan, G. T., Farrow, G. M. and Bostwick, D. G. 1997. Urology 50: 679-684.

10. Maxie, M. G. 1993. pp. 518-522. In: Pathology of Domestic Animals. Vol 2. 4th ed. (Jubb, K. V. F., Kennedy, P. C. and Palmer, N. eds.), Academic Press, San Diego.

11. Meuten, D. J. 2002. pp. 509-524. In: Tumors in Domestic Ani- mals. 4th ed. (Meuten, D. J. ed.), Iowa State Press, Ames.

12. Meuten, D. J., Everitt, J., Inskeep, W., Jacobs, R. M., Peleteiro, M. and Thompson, K. G. 2004. pp. 14-20. In: Histological Classification of Tumors of the Urinary System of Domestic Animals. 2nd series. Vol. XI (Schulman, F. Y. ed.), Armed Forces Institute of Pathology, Washington, D.C.

13. Moll, R., Hage, C. and Thoenes, W. 1991. Lab. Invest. 65: 74 86.

14. Mukhopadhyay, S., Valente, A. L. and de la Roza, G. 2004. Arch. Pathol. Lab. Med. 128: 1404-1411.

15. Murphy, W. M., Beckwith, J. B. and Farrow, G. M. 1993. pp. 132-135. In: Tumors of the Kidney, Bladder, and Related Urinary Structures. Atlas of Tumor Pathology, 3rd series. Fascicle 11 (Rosai, J. and Sobin, L. H. eds.), Armed Forces Institute of Pathology, Washington, D.C.

16. Newman, S. J., Confer, A. W. and Panciera, R. J. 2006. pp. 677-680. In: Pathologic Basis of Veterinary Disease. 4th ed. (McGavin, M. D. and Zachary, J. F. eds.), Mosby, St. Louis.

17. O'Toole, K. M., Brown, M. and Hoffmann, P. 1993. Urol. Clin. North. Am. 20: 193-205.

18. Owen, R. A., Haywood, S. and Kelly, D. F. 1986. Vet. Rec. 119: 291-295.

19. Pomroy, W. 1981. Equine Vet. J. 13: 198-200.

20. Sandusky, G. E., Wightman, K. A. and Carlton, W. W. 1991. Am. J. Vet. Res. 52: 613-618.

21. Shen, S. S., Krishna, B., Chirala, R., Amato, R. J. and Truong, L. D. 2005. Mod. Pathol. 18: 933-940.

22. Traub-Dargatz, J. L. 1998. Vet. Clin. North. Am. Equine Pract. 14: 495-504.

23. Van Amstel, S. R., Huchzermeyer, D. and Reyers, F. 1984. J. S. Afr. Vet. Assoc. 55: 35-38.

24. Van Mol, K. A. C. and Fransen, J. L. A. 1986. Vet. Rec. 119: 238-239.

25. Vitovec, J. 1977. J. Comp. Pathol. 87: 129-134.

26. Vos, J. H., Van Den Ingh, T. S. G. A. M., Misdorp, W., Ramaekers, F. C. S., Van Mil, F. N. and Dd Neijs, M. 1989. J. Vet. Med. A 36: 561-575. 